\title{
Investigation of Various Random Wave Run-up Amounts under the Influence of Different Slopes and Roughnesses
}

\author{
Ali Ebrahimi ${ }^{1}$, Mahdi Behdarvandi Askar ${ }^{2}{ }^{*}$, Sadeq Haqiqi Pour $^{3}$, Vahid Chegini $^{4}$
}

Received: 30.07.2015

\author{
Revised: 28.09 .2015
}

\begin{abstract}
The aim of this study was to investigate the effect of an upstream slope and its roughness on the run-up level of waves. In this study, it was attempted to propose an appropriate and effective solution regarding the issue of wave run-up on seawalls through using a sloping seawall and examining the roughness on these slopes.

The intended slopes for seawalls were $22,27,32,39$ degrees, respectively and had the roughness heights on wall surface were $15 \mathrm{~cm}, 20 \mathrm{~cm}$ and $30 \mathrm{~cm}$. Moreover, four types of roughness layouts on the wall surface were investigated. The results, obtained from investigating the effect of slope and roughness on the run-up level of waves, were analyzed after drawing tables and figures. The results show that by increasing slope gradient of the structure, the run-up level also increases, thus, it can be concluded that the run-up level is directly correlated to the structure gradient. The highest runup level is related to a diagram with a slope of 39 degrees and its lowest level is related to a slope of 22 degrees. Furthermore, the layout type 3 was recognized to be the best layout having the lowest run-up level. The results also revealed that the best and most efficient height for roughness is equal to $30 \mathrm{~cm}$ which has the lowest run-up level in all the slopes and layouts. Moreover, the impact of run-up was investigated according to the geometric shapes of layouts on the seawall surface and the results were presented.
\end{abstract}

Keywords: wave run-up, sloping seawall, roughness height.

\section{Introduction}

Seawalls are structures that are used parallel to and near the shoreline, or in some cases in shallow water areas, to protect the coast and securing coastal buildings and facilities. Seawalls are divided into different types in terms of shape and type of materials used in them. Seawalls are structures that are fully self-reliant in terms of stability and are used in protecting the coast from the wave effects. Unlike the protective coatings that can be built on coastal slopes, seawalls are usually built in areas that are lacking in coastal slopes. Seawalls, based on the materials used in them, can be classified into seawalls using soil, reinforced soil, stone, concrete, and steel shields. The shape of seaward face of seawalls can also be vertical, sloped, and Roughened as well as a variety of curves or a combination of these types (Ahrens. 1981). Seawalls are among the most common and useful constructions to protect the coast in coastal areas, especially in recent years. By the development of research and various modelings, such constructions are now capable of being used in different situations.

\footnotetext{
Author's Address

${ }^{1}$ Khorramshahr University of Marine Science and Technology, Khorramshahr, Iran

${ }^{2}$ Department of Offshore Structures, Khorramshahr University of Marine Science and Technology, Khorramshahr, Iran

${ }^{3}$ Iranian National Institute for Oceanography and Atmospheric Science

${ }^{4}$ Department of Civil Engineering, Khuzestan University Jihad Higher Education Center Email: sazehenteghal@yahoo.com
}

The ruling parameters in the design of coastal structures are divided into three categories of hydraulic parameters, geotechnical parameters and structural parameters. Hydraulic parameters include wave reflection from structures, wave overtopping and transmission as well as wave run-up and rundown (Chegini. 2011). The wave run-up parameter is one of the most important parameters in this study that we intent to examine. When the waves break on the slope of a beach in the surf zone, some wave energy is dissipated by a turmoil caused by breaking the wave and the rest of the energy is dissipated in form of the wave run-up on the beach slope. As a result of the wave impact on the coastal edge face, a certain amount of water is pulled up over the sideline, which is called wave run-up. In other words, the wave run-up is resulted from the wave energy transmission or dissipation which plays a significant role in hydrodynamics of the coastal zone. The vertical distance between the highest water surface level and the static balance is known as the wave run-up level in the coastal area. To estimate water level changes in coastal area, a wave run-up level with $\mathrm{R}_{\mathrm{u} 2 \%}$ is usually used, which means a run-up level exceeded only by $2 \%$ of the run-up amounts.

Studying these aspects of research goes back to the period of the last century (systematic research and with a standard output), which demonstrates the great importance of the issue of run-up. Moreover, it is necessary to note that one still can sense the 
potential to do any research, experiments and modeling in this field despite the bulk of research conducted to date. Most damages in this area directly involve humans' lives, since exploitation in the area of beaches include various sections such as networks of shipping, fishing and recreation that are all continuously connected to the human beings. Therefore, it can be said that examining the amount of run-up will have a significant impact in the field of design, economy and safety. Thus, appropriate methods and strategies should be sought in order for increasing the design level (safety) and decreasing economic costs, since offshore and coastal structures are among the most expensive civil projects. In this regard, appropriate methods and strategies should be accessed so that such projects not only have the most reasonable cost in the construction phase, but the environmental conditions during the life of the structure do not also lead to increased costs of their maintenance. Furthermore, in addition to proposing solutions to prevent erosion, construction of those structures should be desired that in addition to meeting structure and design needs, are aesthetically and visually attractive and can function as tourist attractions.

\section{Materials and Method}

\section{Research background}

Research in the field of the wave run-up cannot be limited to a certain period of time as the problem has existed and sensed since the beginning of the human life along the sea and the occurrences of storm. Since the old years, the mankind attempted in every way to deal with the waves on beaches which indicates a long history of investigating in the field of marine hazards such as storm and sea surges. The first studies on the regular wave run-up were conducted by Grantm (1953), Saville (1955) and Switch (1958). These scholars investigated and measured the run-up amount of regular waves in different circumstances and depicted some diagrams according to the wave run-up against various parameters. However, they did not propose any relationship in order for the wave run-up prediction. Hunt (1959) presented the first practical formula for estimating the run-up of regular waves on a soft and a rough bed. Moreover, Van Der Meer and Stam (1992) investigated the wave run-up by modeling the irregular wave run-up in a sea flume using both permeable and impermeable beds.

\section{The investigated parameters}

The current study explored the impact of existing roughness and slopes on the run-up amount in the seawalls. There were a total of 52 tests carried out on the seawall section. In addition, a number of four slopes with 22, 27, 32, and 39 degrees and four various layouts with three roughness heights of 15 , 20 and $30 \mathrm{~cm}$ are respectively considered in the process of designing this study.

Variables in this section include 4 walls with various slopes and aspects. There are also some Roughness with various shapes (4 types of Roughness) and heights of 15,20 and $30 \mathrm{~cm}$ on their sloping surface. Each slope is marked with letters A, B, C, D and each Roughness is marked with numbers 1,2, 3 and 4, to better understand the issue. The following table presents the marking method of the modeling.

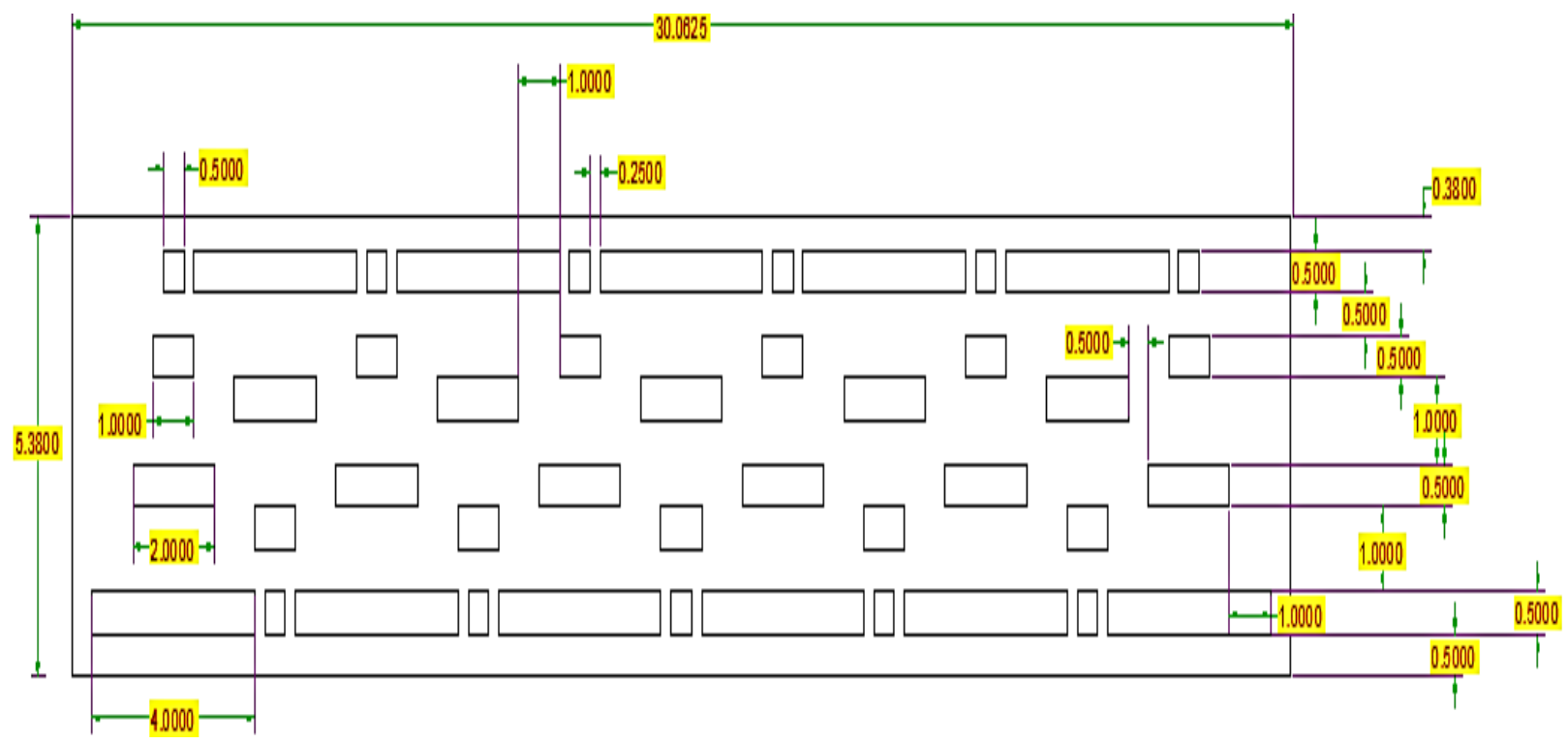

Figure 1 Seawall Type 1 
Investigation of Various Random

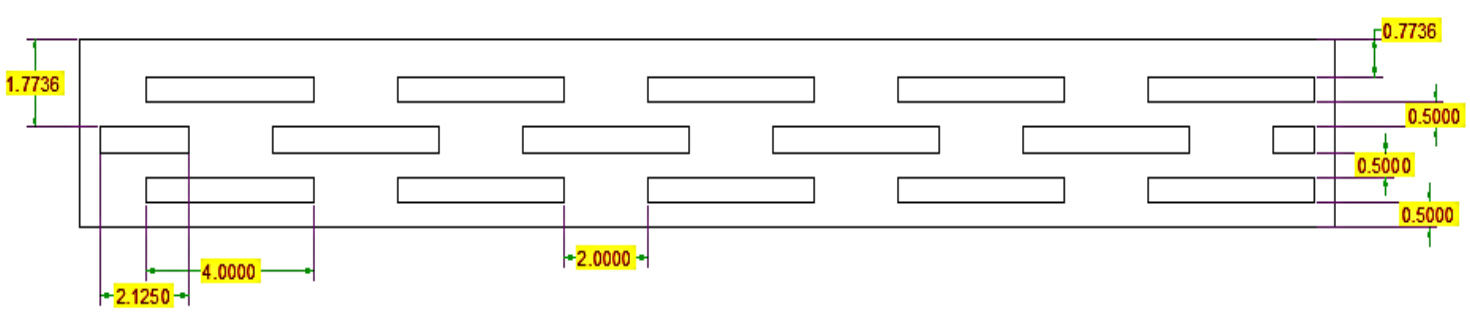

Figure 2 Seawall Type 2

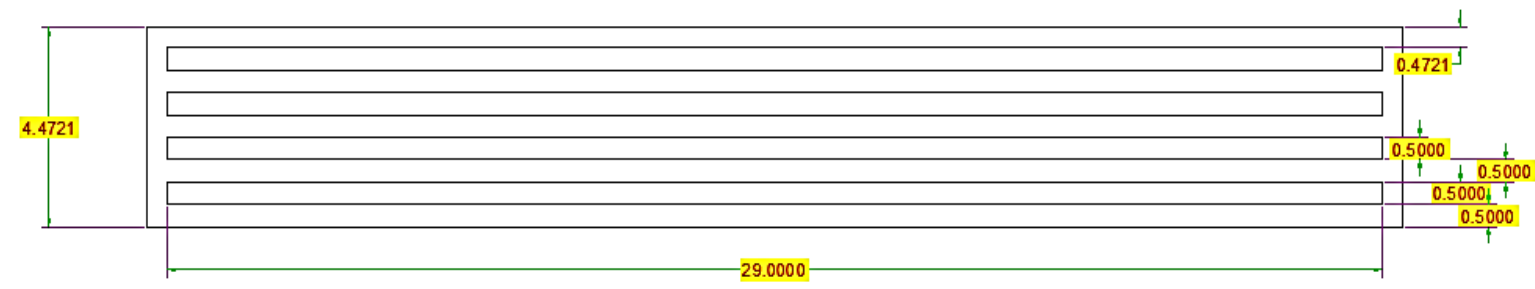

Figure 3 Seawall Type 3

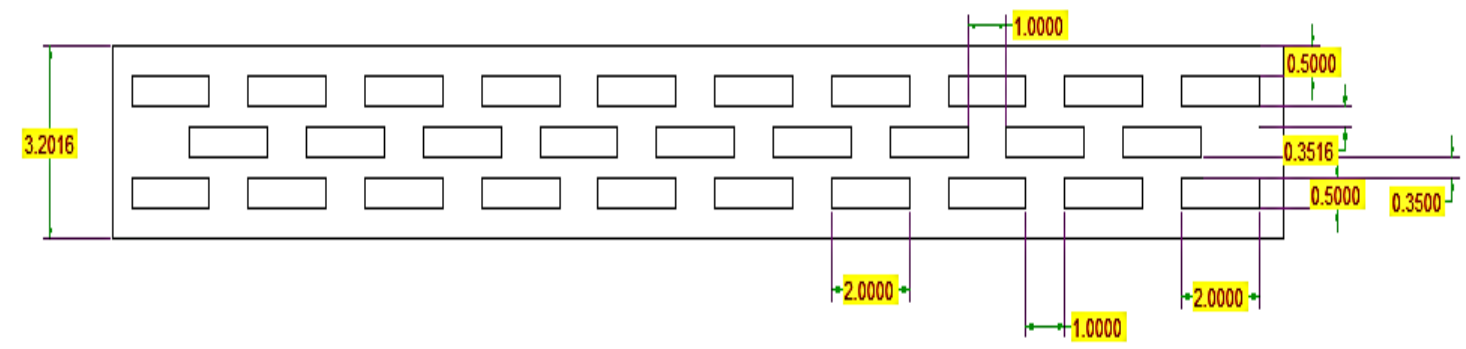

Figure 4 Seawall Type 4

Table 1 The Design of Layouts

\begin{tabular}{|c|c|c|c|c|c|}
\hline \multirow{2}{*}{$\begin{array}{r}\text { Type } \\
\text { of } \\
\text { slope }\end{array}$} & \multirow[b]{2}{*}{ Roughness height } & \multicolumn{4}{|c|}{ Layout design } \\
\hline & & Type 1 & Type 2 & Type 3 & Type 4 \\
\hline \multirow{4}{*}{$\underline{A}$} & Without Roughness & \multicolumn{4}{|l|}{$\mathrm{A} 1$} \\
\hline & $15 \mathrm{~cm}$ & A2-1 & A2-2 & $A 2-3$ & A2-4 \\
\hline & $20 \mathrm{~cm}$ & A3-1 & A3-2 & $A 3-3$ & A3-4 \\
\hline & $30 \mathrm{~cm}$ & A4-1 & A4-2 & A4-3 & A4-4 \\
\hline \multirow{4}{*}{$\underline{B}$} & Without Roughness & \multicolumn{4}{|l|}{ B1 } \\
\hline & $15 \mathrm{~cm}$ & B2-1 & B2-2 & B2-3 & B2-4 \\
\hline & $20 \mathrm{~cm}$ & B3-1 & B3-2 & B3-3 & B3-4 \\
\hline & $30 \mathrm{~cm}$ & B4-1 & B4-2 & B4-3 & B4-4 \\
\hline \multirow{4}{*}{$\underline{\mathrm{C}}$} & Without Roughness & \multicolumn{4}{|l|}{$\mathrm{C} 1$} \\
\hline & $15 \mathrm{~cm}$ & $\mathrm{C} 2-1$ & $\mathrm{C} 2-2$ & $C 2-3$ & $\mathrm{C} 2-4$ \\
\hline & $20 \mathrm{~cm}$ & C3-1 & C3-2 & C3-3 & C3-4 \\
\hline & $30 \mathrm{~cm}$ & C4-1 & $\mathrm{C} 4-2$ & C4-3 & C4-4 \\
\hline \multirow{7}{*}{$\underline{\mathrm{D}}$} & Without Roughness & \multicolumn{4}{|l|}{ D1 } \\
\hline & $15 \mathrm{~cm}$ & D2-1 & $\mathrm{D} 2-2$ & D2-3 & D2-4 \\
\hline & $20 \mathrm{~cm}$ & D3-1 & D3-2 & D3-3 & D3-4 \\
\hline & $30 \mathrm{~cm}$ & D4-1 & D4-2 & D4-3 & D4-4 \\
\hline & & \multicolumn{2}{|c|}{ Degree- size } & Number & Variables \\
\hline & & \multirow{2}{*}{\multicolumn{2}{|c|}{$22-27-32-39$}} & 4 & Wall slope \\
\hline & & & & 4 & Layout design \\
\hline
\end{tabular}




\section{Results and Discussion}

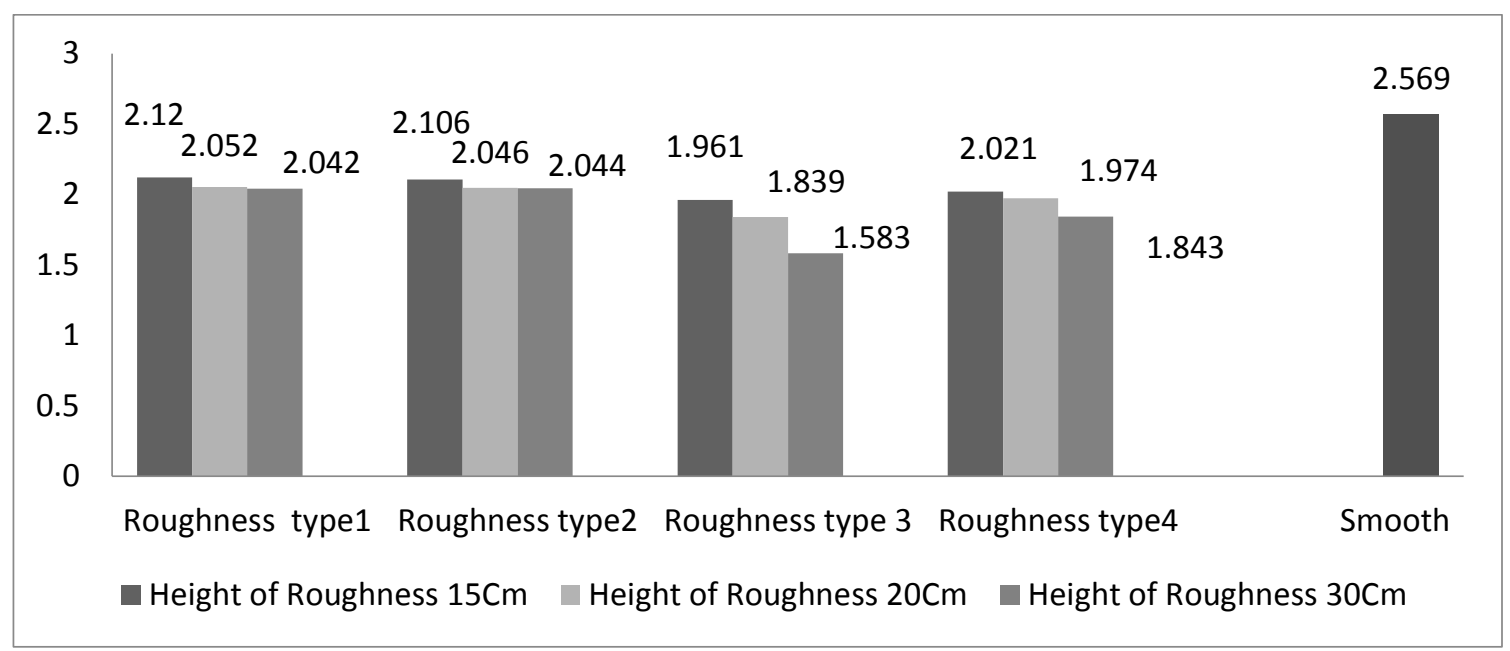

Figure 5 the seawall run-up Type A (slope of 39 degrees)

The obtained results are compared to each other in Figures 5 to 8 in terms of the gradient changes which is considered to be the basis of comparison and analysis of the results

According to Figure 5, for the slope of 39 degrees and three roughness heights of 15,20 and $30 \mathrm{~cm}$, we come to the conclusion that we have managed to reduce the run-up amount by creating a roughness on the seawall surface. The results of the Figures indicate that there are no significant differences in the gradient changes as well in the increased height of Roughness in the layouts Type 2, 1, and 4. Moreover, the run-up changes of the waves in these three layout types with three types of roughness height and a slope of 39 degrees have a difference of a few centimeters. The noteworthy point in these shapes is that the differences are more significant and obvious in the layout Type 3, and this layout contains the highest percentage of the run-up reduction with an increased height of Roughness, especially the wall with the layout Type 3 and the Roughness height of $30 \mathrm{~cm}$. These results indicate that although the run-up declines in the seawalls with an increase in the Roughness height, the layout affects the result, and such a runup reduction in various layout designs can be found to be different. Moreover, the run-up amount can be significantly reduced by a layout design as well as a systematic height change.

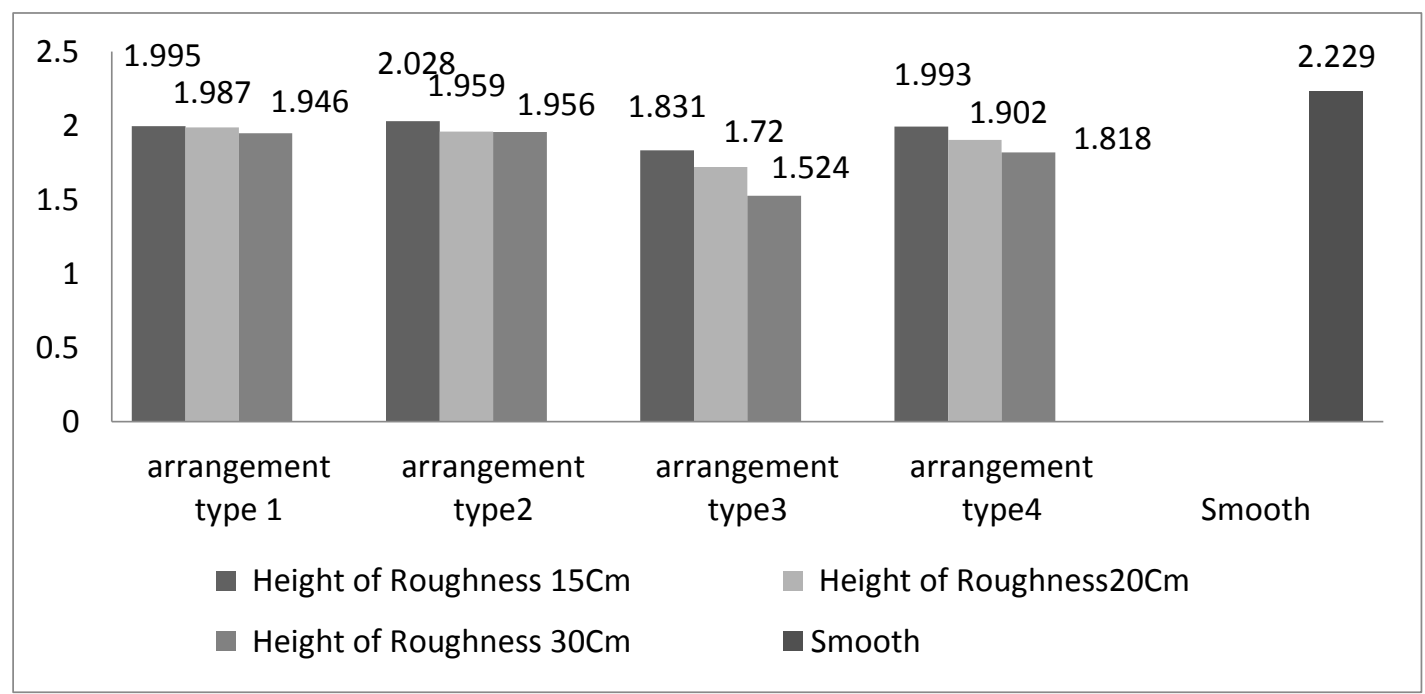

Figure 6 the seawall run-up amount Type B (slope of 32 degrees) 
According to Figure 6, the run-up amount in the slope of 32 degrees has declined in the seawall compared to the slope of 39 degrees. Moreover, if in this slope, the run-up results between the Rough less(smooth) mode and various Roughness heights are compared with each other, it can be seen that by creating a roughness on the seawall, the run-up amount has declined substantially. In accordance with the shapes relevant to the seawall with a slope of 32 degrees, the layout Type 3 is considered the best layout design.

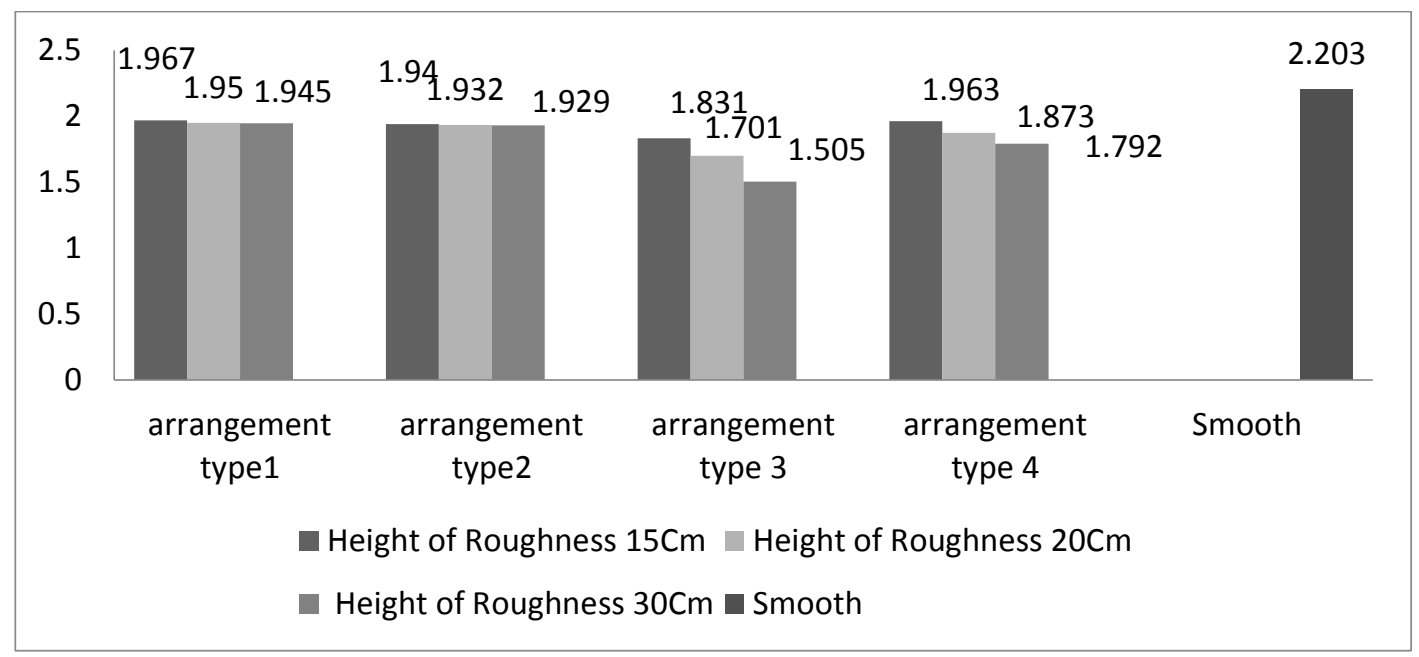

\section{Figure 7 the seawall run-up amount Type $C$ (slope of 27 degrees)}

According to Figure 7, it is observed that the runup amount in three heights of 15, 20 and 30 in the layouts Type 1 and 2 are very close to each other and the difference between them is only about a few hundred meters. Moreover, the greater we go towards the layout Type 3, the greater the impact of the roughness height becomes and it reaches its highest degree. However, this amount declines in the layout Type 4. Although, there is no significant difference between the height change in the roughness and the height difference is about 5 to 10 centimeters, they have different impacts in different layouts. For example, the greatest difference in the run-up amount among three heights of roughness can be seen in the layout Type 3, and the least difference is also related to the layout Type 1 .

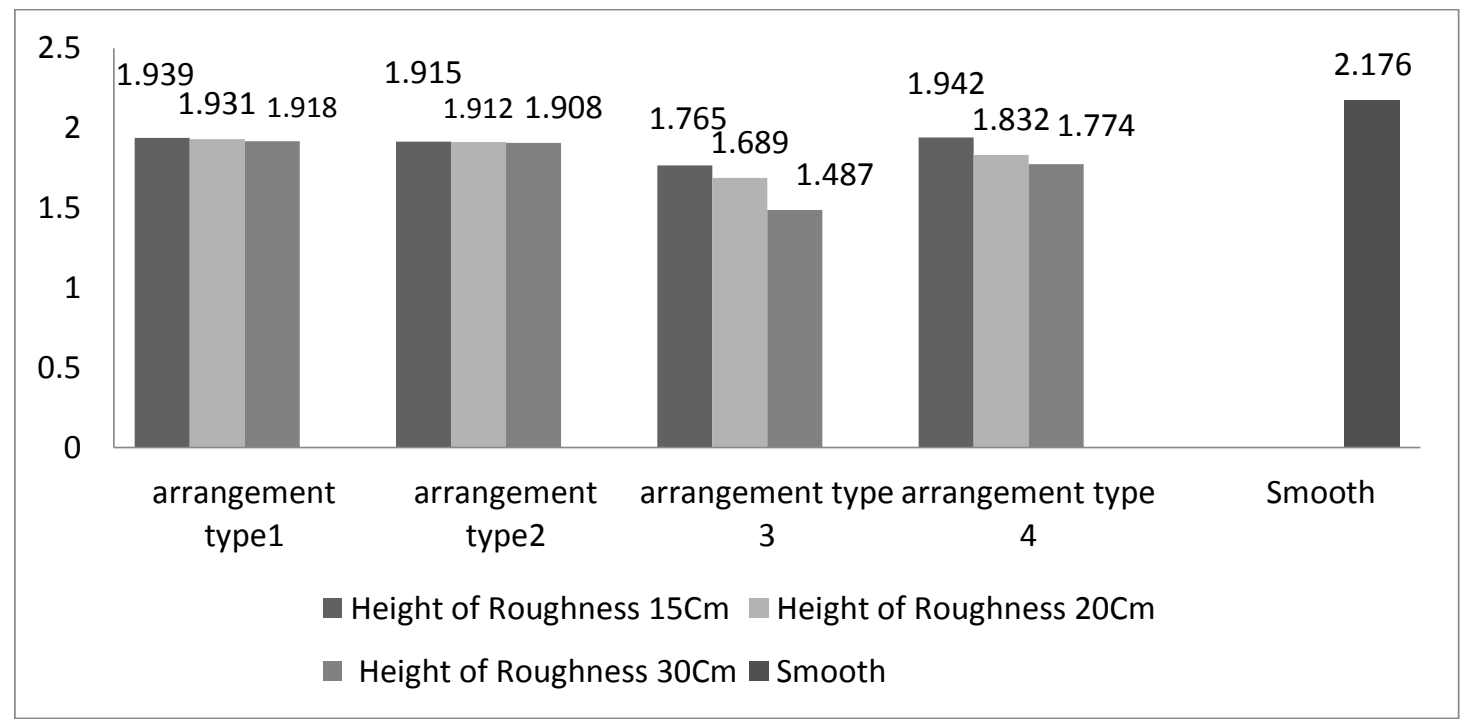

Figure 8 the seawall run-up amount Type D (slope of 22 degrees)

As can be seen in Figure 8, the height changes of roughness have the lowest impact in the 22-degree slope which is obtained by comparing all four types of slope with each other. According to the 


\section{Ebrahimi et al.}

Figure, we conclude that the best layout design is the layout design Type 3 with the lowest run-up amount which has the greatest influence relative to the height change. Furthermore, the lowest impact rate of the height of roughness is in the layouts Type 1 and Type 2 and then in the layout Type 4 . If we examine the results in terms of height changes of the roughness on the seawall, we find out that the results in Figures 5 to 7 are presented based on comparative figures and indicators to better indicate the height changes of the roughness on the seawall and their rate of impact in the reduction of overtopping caused by waves.

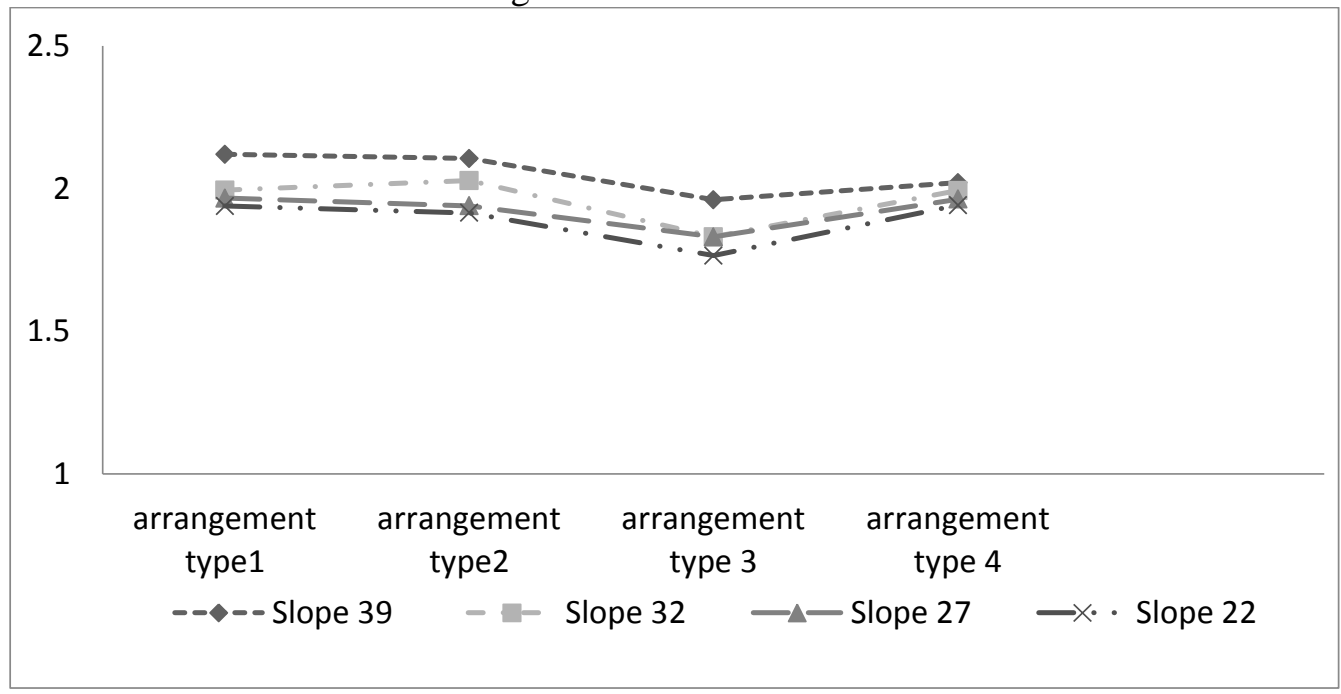

Figure 9 the seawall run-up amount for a 15-cm Height of Roughness and different slopes

According to Figure 9, comparing the roughness height of $15 \mathrm{~cm}$ in 4 different slopes indicates that the run-up amount increases with an increase of the slope in this height. Moreover, the highest run-up amount is seen in the slope of 39 degrees and the lowest run-up amount is observed in the seawall with a slope of 22 degrees. As can be seen in the comparative Figure, the impact of slope is different for different layouts. In layout Type 1, the slope change has the greatest impact for the seawall with a height of $15 \mathrm{~cm}$, and the slope impact decreases as we go towards the layout Type 4, and they are relatively close to each other in the layout Type 4 . It reveals that the height of $15 \mathrm{~cm}$ has the lowest impact on the layout Type 4.

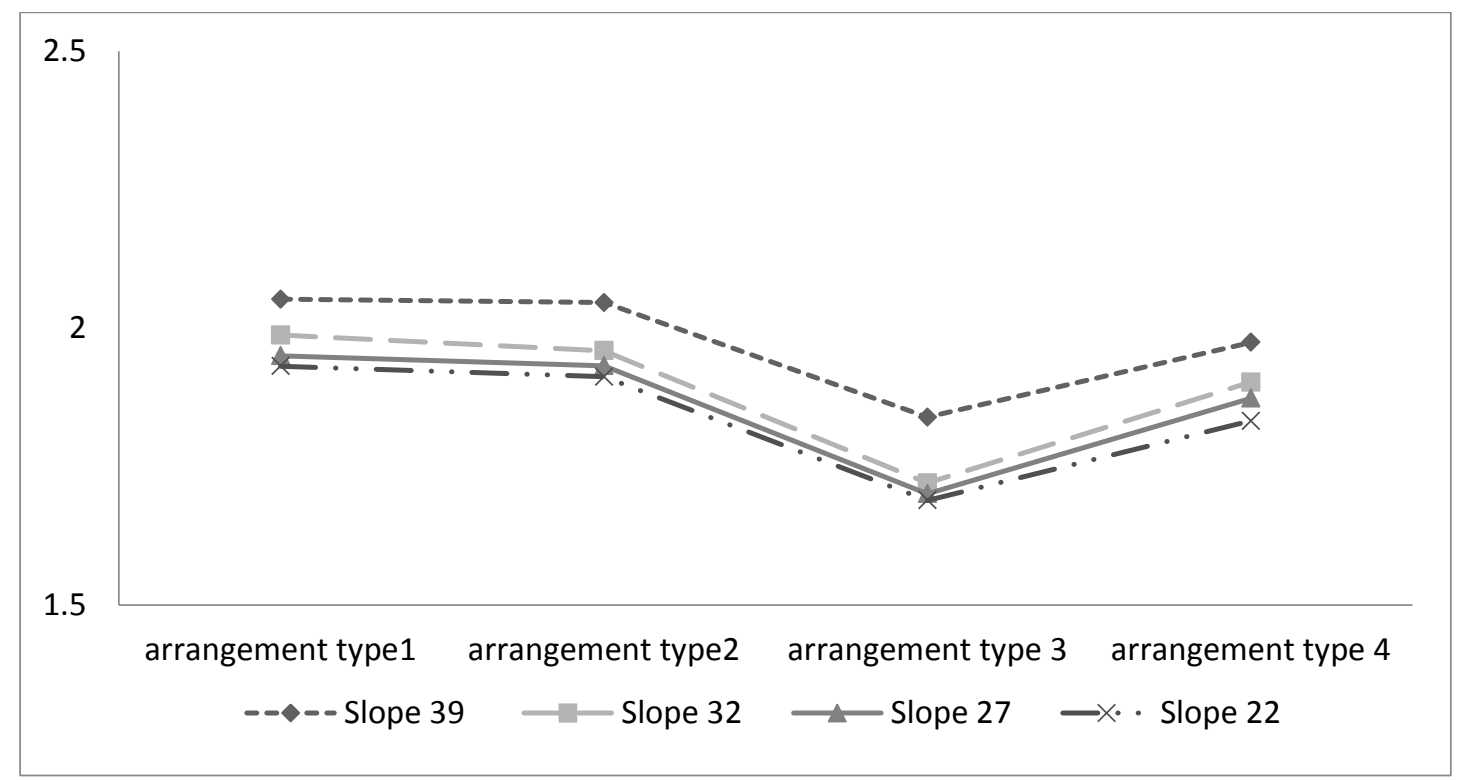

Figure 10 the seawall run-up amount for a 20-cm Height of Roughness and different slopes 
The results obtained from Figure 10, again emphasize this point that in the roughness height of $20 \mathrm{~cm}$, the run-up amount increases with an increase in the seawall slope. However, the significant thing in this roughness height is that in all the four layout designs, diagrams related to the slopes of 27, 22 and 32 degrees have a significant closeness to each other than the slope of 32 degrees. The conclusion can be drawn from this point that in the roughness height of $20 \mathrm{~cm}$, the seawall slope has a greater impact, and given that there is an insignificant difference in the runup amount among the three slopes of 22, 27 and 32 degrees, one can make use of the slope of 22 degrees instead of using the slopes of 27 and 32 degrees, and decrease the operation volume.

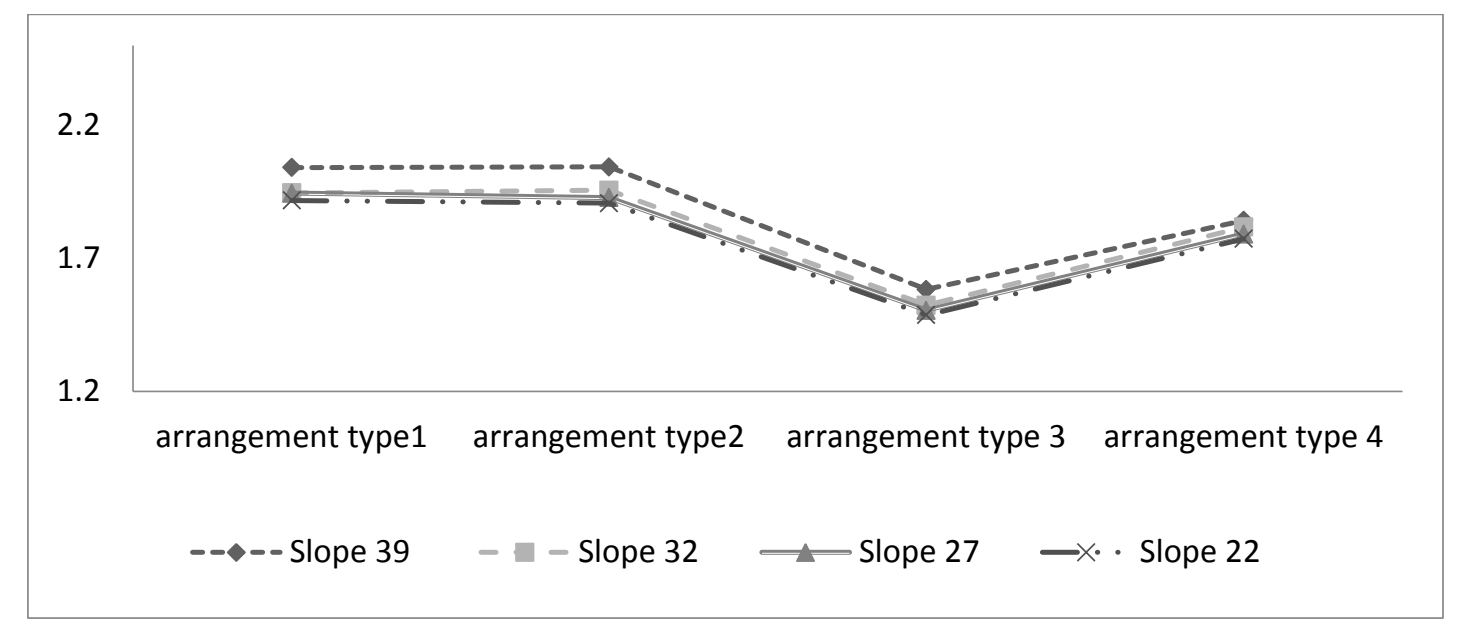

Figure 11 the seawall run-up amount for a 30-cm Height of Roughness and different slopes

According to Figure 11 and the comparative Figure, a very significant point that can be observed is that the comparative diagram of the seawall with a roughness height of $30 \mathrm{~cm}$ contains all the conditions and results obtained from the diagrams related to the seawall with roughness heights of 15 and $20 \mathrm{~cm}$. That is, according to the roughness height of $15 \mathrm{~cm}$, the difference of the run-up amount in various slopes is significantly reduced as we go towards the layout Type 4 so that they are almost adapted on each other. Another result, which is highly similar to the results obtained from the seawall with a roughness height of $20 \mathrm{~cm}$, is that the runup amounts are highly close to each other in the three slopes of 22, 27 and 32 degrees, and these two utmost important results together exist in the $30-\mathrm{cm}$ height indicating that the roughness height of $30 \mathrm{~cm}$ is the best and most optimal height.

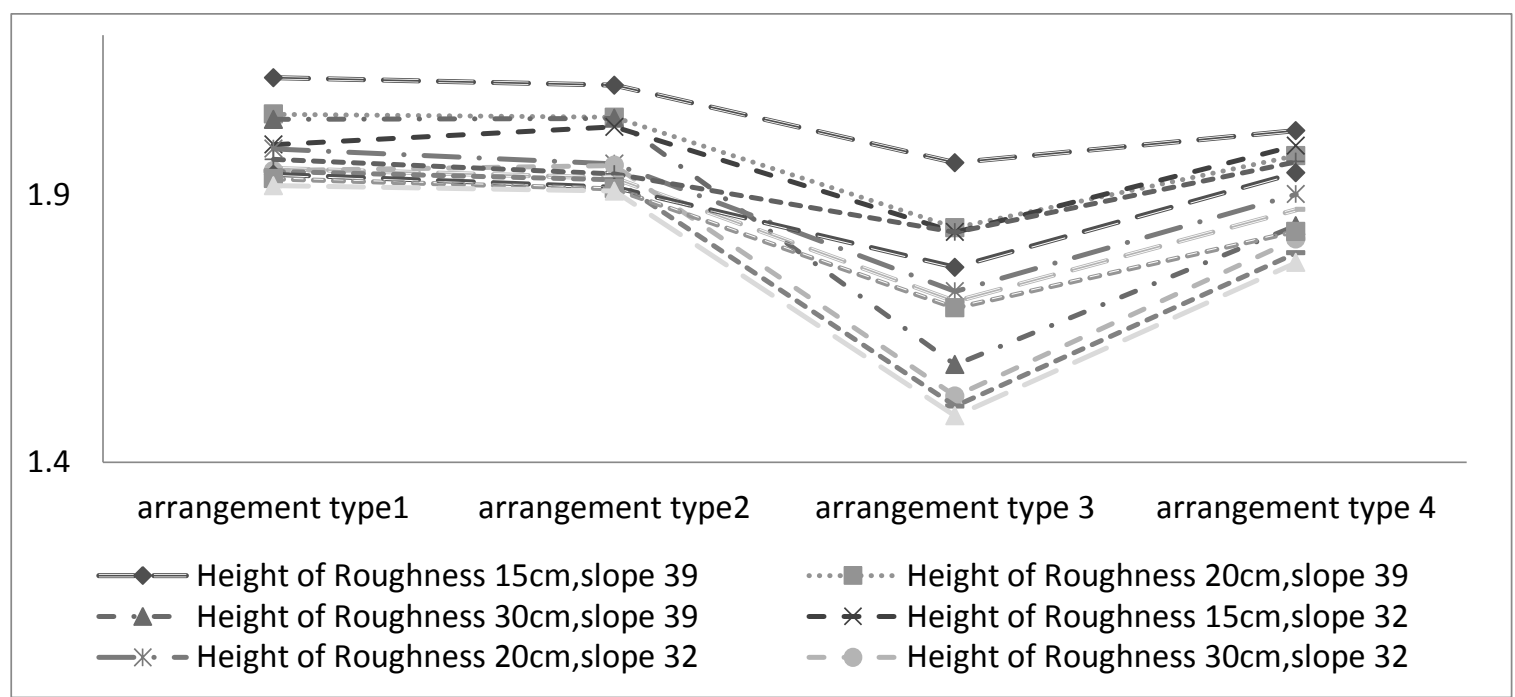

Figure 12 the seawall run-up amount for $15-\mathrm{cm}, 20-\mathrm{cm}$ and $30-\mathrm{cm}$ Height of Roughness and different slopes 
As is clear from Figure 12, by increasing the slope, the run-up amount also increases. Moreover, it was revealed that the greatest run-up belongs to the diagram with a slope of 39 degrees and the lowest run-up belongs to the diagram with a slope of 22 degrees. Moreover, the layout Type 3 is considered the greatest layout design, and then the layout designs 4, 2 and 1 can be sorted in order of increasing the run-up. Furthermore, the highest run-up amount is related to the modeling A2-1 (seawall with a slope of 39 degrees and with a height of $15 \mathrm{~cm}$ and the layout Type 1) and the lowest run-up amount is related to the modeling B4 - 3 (seawall with a slope of 22 degrees and the roughness height of $30 \mathrm{~cm}$ and the layout Type 3) which is also the best modeling state. In the layout type 2, the slopes of 22, 27 and 32 degrees are closer to each other from which it can be concluded that in the layout Type 2, one can make use of the slope of 22 degrees instead of using the slopes of 27 and 32 degrees, and decrease the operation volume.

\section{References}

Ahrens JP. 1981. Irregular wave run-up on smooth slopes. CETA NO. 81-17. U.S. Army corps of engineers. Ft. Belvoir(VA): coastal Engineering Research center. 57

Granthem, K.N., 1953. A model study of wave run-up on sloping structures, technical Report, Series 3,Issue 348, Institute of Engineering, Research, University of California, Berkeley, California.

Hunt, I. A., Jr. 1959. "Design of seawall and breakwaters." J.Wtrwy. and Harb. Div., ASCE, 85(3), 123-152.

Savage, R.P., 1958. Wave run-up on roughened and permeable slopes. Journal of the Waterways and Harbors Division, vol. 84, no. WW3. American Society of Civil Engineers, pp. 1640-1-1640-38.

Saville Jr., T., 1955. Laboratory data on wave run-up and overtopping on shore structure, Technical Memorandum No. 64, Beach Erosion Board, U.S. Army Corps of Engineers, Washington, DC.

Van Der Meer, J.W., Stam, C. J.M., 1992. Water run-up On smooth and rock slopes of coastal structures. Journal of waterway, Port, coastal, and Ocean Engineering vol. 118, no. American Society of Civil Engineers, pp. 534-550. 